\title{
Impact of road traffic noise annoyance on health-related quality of life: results from a population-based study
}

\author{
Julia Dratva $\cdot$ Elisabeth Zemp $\cdot$ Denise Felber Dietrich • \\ Pierre-Olivier Bridevaux $\cdot$ Thierry Rochat • \\ Christian Schindler • Margaret W. Gerbase
}

Accepted: 13 December 2009/Published online: 1 January 2010

(C) Springer Science+Business Media B.V. 2009

\begin{abstract}
Purpose To estimate the impact of traffic-related noise annoyance on health-related quality of life (HrQoL) in a population-based study and potential effect modification by gender.

Methods The study included 5,021 participants of the Swiss Cohort Study of Air Pollution and Lung Disease in Adults second survey. The association between trafficrelated noise annoyance, measured on an 11-point scale, and HrQoL, based on SF-36 scores, was investigated by multivariate regression analysis. Effect sizes were calculated, and interactions by gender and chronic disease status examined.

Results Thirteen percentage of the study population reported high annoyance due to traffic. Women were more likely to report high noise annoyance (adjOR 1.23 ; 95\% CI 1.01-1.48). Except for general health, all SF-36 scores showed a significant negative association with noise annoyance. The respective effect sizes ranged between 0.13 and 0.54 . Significant effect modification by gender and chronic disease status was present in specific SF-36 domains.
\end{abstract}

Electronic supplementary material The online version of this article (doi:10.1007/s11136-009-9571-2) contains supplementary material, which is available to authorized users.

J. Dratva $(\varangle)$ - E. Zemp · D. F. Dietrich · C. Schindler Institute of Social and Preventive Medicine at Swiss Tropical Institute, Associated Institute of the University of Basel,

Steinengraben 49, 4051 Basel, Switzerland

e-mail: julia.dratva@unibas.ch

P.-O. Bridevaux · T. Rochat $\cdot$ M. W. Gerbase

Division of Pulmonary Medicine, University Hospital of

Geneva, 24 rue Micheli-du-Crest, 1211 Geneva 4, Switzerland
Conclusion This paper presents first evidence of an inverse relationship of noise annoyance and $\mathrm{HrQoL}$ in a general population. Although the estimated effects are small to moderate for individuals, they may add up to a relevant public health impact.

Keywords Epidemiology - Noise - Noise annoyance · Gender - Health-related quality of life

$\begin{array}{ll}\begin{array}{l}\text { Abbreviations } \\ \text { adjOR }\end{array} & \begin{array}{l}\text { Adjusted Odds ratio } \\ \text { Body mass index }\end{array} \\ \text { BMI } & \text { Health-related Quality of life } \\ \text { HrQoL } & \text { Likelihood ratio test } \\ \text { lrtest } & \text { Swiss cohort study on air pollution and lung } \\ \text { SAPALDIA } & \text { diseases in adults } \\ \text { SF-36 } & \text { 36-Item short-form health survey }\end{array}$

\section{Introduction}

Traffic noise is an increasing problem in our modern society and the dominating source of noise in urban environments [1]. Noise, an "unwanted sound" [2], is perceived as a nuisance and environmental stressor. Up to two-thirds of the Swiss population are annoyed about traffic-related noise [3]. Noise is an objectively quantifiable environmental exposure that can trigger individual reactions and symptoms with the potential development of adverse health outcomes. An increasing body of literature has shown traffic noise to have adverse short- and longterm health effects [4-7]. The transformation from an environmental exposure to an individual's internal state of 
noise-related stress is modulated by personal as well as situational factors and mediated by neuro-vegetative and endocrine processes [2,8-10]. Noise annoyance expresses the degree of dissatisfaction and disturbance with regard to noise exposure $[11,12]$ and can be seen as a pathway to the development of health effects as well as a health effect by its own [9]. The assessment of health-related quality of life (HrQoL), as a measure of mental and physical health, constitutes a well-accepted construct to capture the overall effects of environmental factors on the individual's general health. Figure 1 depicts a concept for the impact of noise exposure on health and specifically HrQoL, adapted from a model by Guski [11]. According to the noise-stress model, noise annoyance, as a subjective measure of noise exposure, might be more closely related to the health outcomes than objective measures [13], since noise annoyance captures the specific susceptibility and vulnerability of individuals to noise, which plays an important role in nonauditory health effects [14].

The role of gender in noise perception and annoyance is inconclusive. Several studies have observed higher noise annoyance scores among women $[15,16]$; however, others did not find any gender differences [17]. Gender differences in HrQoL, on the other hand, have been documented by many studies. Women tend to report a lower HrQoL than men [18-22]. Moreover, the importance of different determinants of HrQoL can vary by gender [20, 22-24], and measures of HrQoL themselves can have a different prognostic value in men and women [25].

There has been increased interest in measuring the patient's perceived health in the evaluation of the burden of a disease or the health benefits of a treatment. HrQoL is being used in clinical studies [25-28] as well as in population monitoring of health [19, 29]. It is increasingly accepted that the environment plays a role in well-being and health perception. However, only a few studies have explored the impact of environmental exposures, such as environmental tobacco exposure [24] or neighborhood environment, e.g. community noise, trash and odors [30], on HrQoL. Traffic noise emissions are ubiquitous, and traffic noise exposure is a common concern. Although nonspecific, HrQoL is recognized as a good parameter to assess the self-perceived short- and long-term health effects. The aims of this study were to investigate the association between traffic-related noise annoyance and HrQoL, and whether the effect of noise annoyance differs in men and women.

The rich data set of the SAPALDIA (Swiss cohort study on Air Pollution and Lung Disease In Adults) cohort offers a very good opportunity to investigate this potential association providing information on confounders such as chronic health conditions, lifestyle factors, employment, education and age.

\section{Methods}

The study sample for the analyses included 5,021 participants including men and women, aged 28-72, from the second survey of the SAPALDIA cohort study carried out in 2001/2002, who filled out the 36-item health survey (SF-36). The SAPALDIA cohort, initially conducted to
Fig. 1 Conceptual model of non-auditory effects of environmental noise and noise annoyance [11]

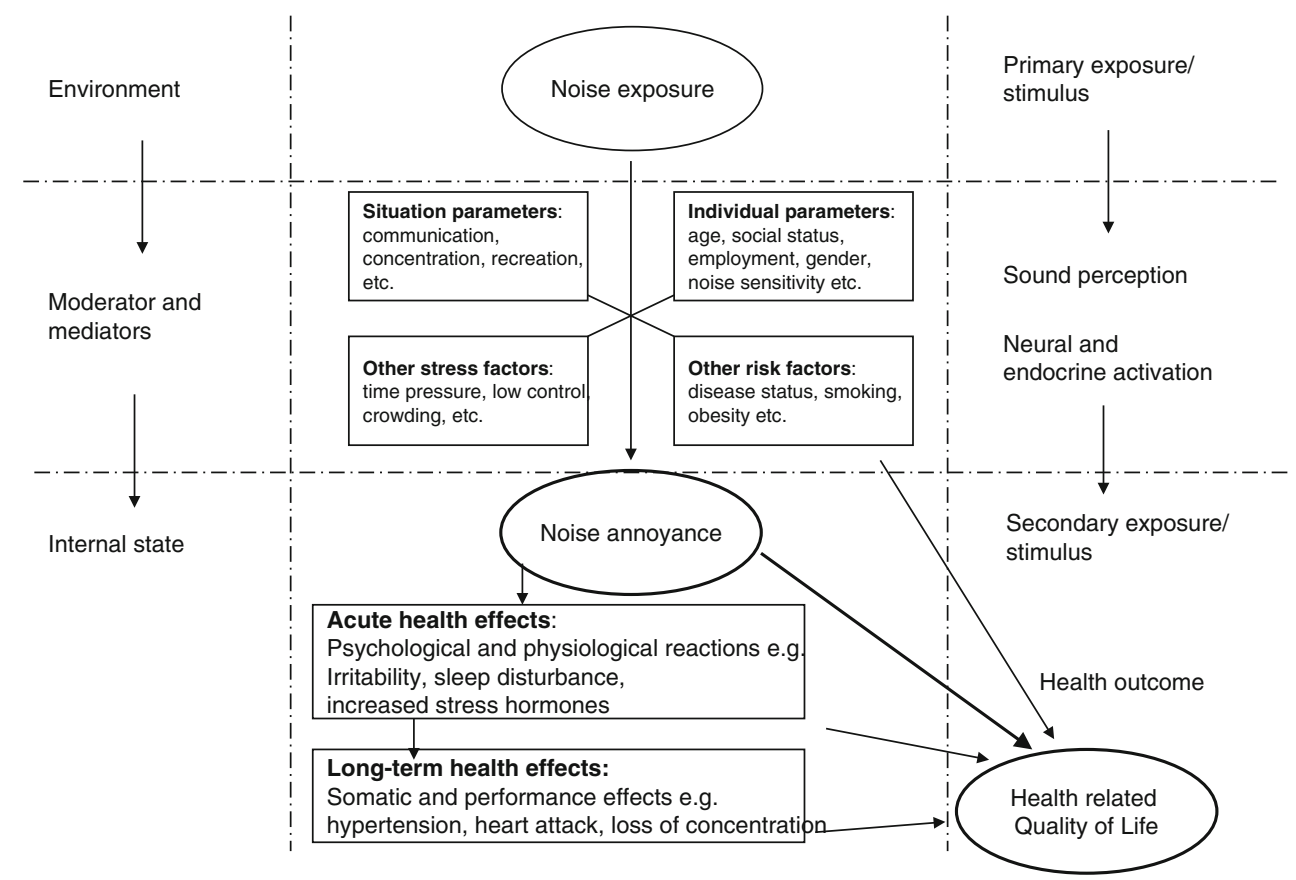


investigate adverse effects of air pollution on lung health, has been described in detail in earlier publications [31, 32]. In short, the SAPALDIA study population was recruited in 1991 as a population-based, random sample of adults (18-60 years) from eight study centers in Switzerland, representing a broad range of environmental conditions. The study was approved by the central ethics committee of the Swiss Academy of Medical Sciences and each center's regional ethics committee and is in accordance with the ethical standards laid down by the 1964 Declaration of Helsinki. Written informed consent was obtained from all participants.

The detailed health assessment included, among others, the SF-36 questionnaire and a main questionnaire which provided information on socio-demographic characteristics, lifestyle factors, living and housing characteristics, health status and on traffic-related noise annoyance. The follow-up survey enrolled 8,047 participants (86\% of surviving SAPALDIA subjects), of which $70 \% \quad(5,672)$ responded to the comprehensive questionnaire and completed the SF-36. For the analytic sample, persons with missing information on noise annoyance $(n=88)$ and participants who reported deafness $(n=563)$ were excluded.

The outcome under investigation, HrQoL, was measured by the SF-36 translated into the three main languages of Switzerland: German, French and Italian [33-35]. The SF-36 is made of 36 items measuring health in 8 dimensions: Physical Functioning (PF), Role Physical (RP), Bodily Pain (BP), General Health (GH), Vitality (VT), Social Functioning (SF), Emotional Role (RE) and Mental Health $(\mathrm{MH})$. For each dimension, a score ranging from 0 (worst state of health) to 100 (best state of health) was calculated. Component summary scales, Physical (PCS) and Mental Component Summary (MCS), were derived according to algorithms specified by the original developers and standardized to have a mean of 50 and standard deviation of 10 , with higher scores representing a better health measure [36].

The exposure of interest, traffic-related noise annoyance, was measured with the question: "How annoying is the noise from traffic in your home when the windows are open?" The degree of noise annoyance was measured by a thermometer scale ranging from 0 (not at all) to 10 (strong and unbearable, Fig. 2) [10, 37-39]. We created a dichotomous noise annoyance variable, defining high noise annoyance as a value of $>6$ on the original 11-point scale, similar to the dichotomization presented by $\mathrm{Li}$ et al. and Conzelmann-Auer et al. [10, 37]. Participants who reported no noise annoyance were considered as the baseline level (noise annoyance value $=0$ ) and used as reference group in further analyses. For the multivariate analysis, the noise annoyance exposure was primarily categorized into six categories: $0=0,1=112 ; 2=314 ; 3=5 \mid 6 ; 4=718$; $5=9110$. Linear spline functions were used to describe the relations between average SF36 scores and these categories.

Patients were asked whether they had a chronic disease, and if yes, whether it was diagnosed by a doctor. Indicator variables for different doctor diagnosed chronic diseases (hypertension, heart disease, stroke, diabetes, migraine, asthma, chronic bronchitis/lung emphysema, kidney disease, arthritis and depression) were considered as main confounders. Participants were defined as chronically sick, if a doctor diagnosed chronic disease was reported, and otherwise as healthy. Further, general health indicators (smoking status, environmental tobacco smoke exposure, physical activity or body mass index (BMI)), sociodemographic characteristics (age, education, employment status and study center), information on housing and neighborhood (based on questions on the type of home, number of persons living in the same home, years of residency, urbanity of the neighborhood and self-reported traffic in front of the home and in the neighborhood) and distances from home to different streets [computed using VECTOR25 (www.swisstopo.ch, ArcGIS Version 9.0)] were considered as confounders. Gender was investigated as a potential effect modifier.

\section{Statistical analyses}

In a first step, we assessed the prevalence of traffic-related noise annoyance and the distribution of its various levels in the study population and by gender. Differences between participants who responded to the noise annoyance questions and those who did not were assessed by chi-squared tests.

To better characterize the exposure to traffic-related noise annoyance, its determinants were first investigated in bivariate analyses and then using a multivariate logistic regression model where the dichotomized noise variable was the outcome. The selection of covariates for this model was based on literature, biological plausibility and testing of the significance of bivariate associations. The selection of covariates to be retained in the final model was based on stepwise backward selection at an alpha level of 0.2. This threshold suggested by Hosmer and Lemeshow [40] leads to similar results as a selection procedure based on the Akaike information criterion, thus providing good crossvalidation performance. The final model on determinants of traffic-related noise annoyance included sex, age, BMI, smoking status, occupation, educational status, type of home, numbers of persons in home, years of residency, double-glassed windows, neighborhood, car and heavy vehicle traffic in front of home. 
Fig. 2 Reported noise annoyance in the 2002 SAPALDIA cohort by gender. Categories correspond to following rating scales: $0=0$; $1=1,2 ; 2=3,4 ; 3=5,6$; $4=7,8$ and $5=9,10$

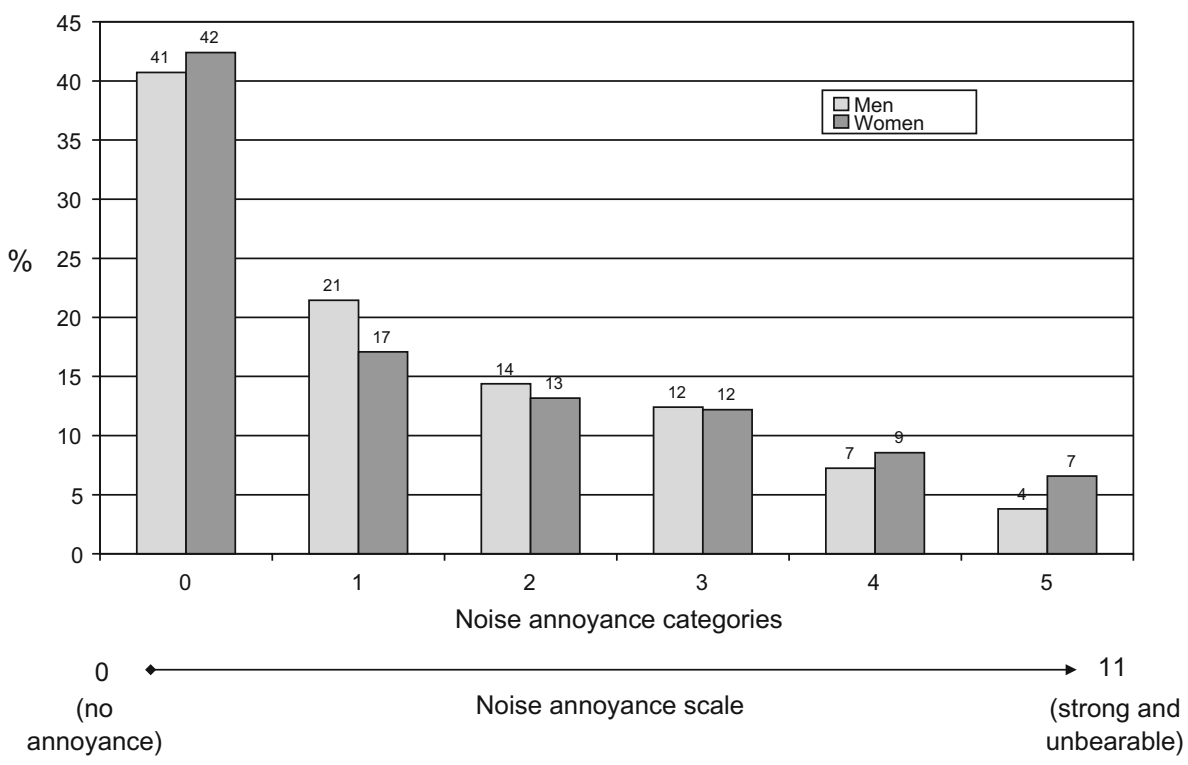

Secondly, we calculated the multivariate regression models to investigate the relationship of traffic-related noise annoyance and $\mathrm{HrQoL}$ with the categorical noise annoyance variable as the independent variable and the SF 36 domains, MCS and PCS as separate dependent variables adjusting for major potential confounders. Whether or not a covariate was considered for the common multiple model to be used for all domains depended on the statistical significance of its bivariate associations with MCS and PCS. All eligible variables were then subjected to a stepwise backward selection process (likelihood ratio test, $P<0.20$ ). A forward selection procedure resulted in the same selection of covariates (likelihood ratio test, $P<0.20$ ). The final model on the association of HrQoL and traffic noise annoyance included sex, age, BMI, smoking status, physical activity, neighborhood, double-glassed windows, persons in household, employment status, study area and doctor diagnosed chronic diseases (hypertension, heart disease, stroke, diabetes, migraine, asthma, chronic bronchitis/lung emphysema, kidney disease, arthritis and depression) along with the respective variable of noise annoyance.

Since the data suggested non-linear associations of MCS and PCS with noise annoyance, after testing different transformations and parabolic functions, we considered linear spline functions of the noise annoyance scores. Spline functions are piecewise polynomials used to fit a non-linear function. Splines provide a flexible tool for describing the complex non-linear associations. Moreover, compared to simple polynomial functions (including simple regression lines) they can better adapt to local phenomena, which makes them less sensitive to influential observations. Initial break points were placed at the boundaries of the noise annoyance categories and then subjected to a backward selection procedure with an alpha level of 0.2 .

Separate spline models were calculated for each SF-36 domain, MCS and PCS. Potential interactions of trafficrelated noise annoyance with sex, chronic diseases and time of residency were assessed by considering models with group-specific spline functions. Models were compared using likelihood ratio tests. In case of significant interactions, we conducted stratified analyses. Further, we estimated the adjusted effect sizes for each SF-36 domain and the summary scales by dividing the difference in the adjusted mean score between the group of highly exposed and the group not exposed to traffic noise annoyance by the root mean squared error (RSME) of the underlying model.

\section{Results}

Study population characteristics

We found significant differences in participants' characteristics by gender (online-supplement Table 1). Female study participants were less educated compared to male participants (high educational status 18 vs. $36 \%, P<0.001$ ) and less often employed (62 vs. $82 \%, P<0.001$ ). A higher percentage of women were widowed or divorced (18 vs. $8 \%$, $P<0.001$ ). More male participants currently smoked (34 vs. $25 \%, P<0.001)$ and consumed alcohol daily (29 vs. $14 \%, P<0.001)$. They had a higher median BMI than women (26 vs. $24, P<0.001$ ). Women, however, were less physically active (47 vs. $38 \%, P<0.001$ ). Doctor diagnosed chronic illnesses were reported more frequently by women than men (46 vs. $38 \%, P<0.001$ ). In addition, 
participants' living and housing characteristics differed by gender (Table 1).

Traffic-related noise annoyance

Thirteen percentage of the study participants reported high noise annoyance (annoyance level $\geq 7$ ). Women reported a significantly higher degree of noise annoyance than men in bivariate analyses (Fig. 2, $P<0.001$ ), consistent with women reporting more traffic and living in areas associated with higher noise exposure. The exposure variable, noise annoyance, and the self-reported truck and car traffic variables were correlated. However, noise annoyance could not be sufficiently characterized by the self-reported data on traffic. Gender remained significant in the multivariate model on determinants of high noise annoyance, adjusting for other socio-demographic characteristics and living and housing conditions (adjOR 1.23; 95\%CI 1.01-1.48). The multivariate model yielded further factors associated with high noise annoyance: age, with significantly decreased odds of high noise annoyance in older participants (>49 years), and the neighborhood environment. Subjects living in the countryside were significantly less likely to be highly annoyed by noise than subjects living in a location with heavy traffic. (adjOR 0.42; CI 95\% CI 0.24-0.74). High noise annoyance was significantly associated with reported intensity of traffic. Compared to light traffic, the odds ratio of high noise annoyance for moderate traffic equaled 1.82 (95\% CI 1.38-2.39) and it reached 4.04 (95\%CI 2.83-5.75) for heavy traffic. Similarly, truck traffic was associated with increased odds of high noise annoyance (infrequent: adjOR 1.46; 95\%CI 1.09-1.95, constant: adjOR 3.2; 95\%CI 2.174.82 compared to never). In comparison with normal weight participants, subjects with a BMI 25-29 (overweight) or $\mathrm{BMI} \geq 30$ were less likely to report a high level of noise annoyance (adjOR 0.85; 95\%CI 0.691-1.04 and adjOR 0.65 ; 95\% CI 0.45-0.81, respectively). Conversely, a higher odds was seen in underweight individuals (BMI $\leq 18.5$, adjOR 1.66; 95\%CI 0.821-3.053). No significant association was found for smoking. Higher educational status showed a significant association with high noise annoyance (adjOR 1.52; 95\%CI 1.02-2.26) when compared to lower educational status.

HrQoL and traffic-related noise annoyance

In multivariate analyses, HrQoL scores showed significant negative associations with traffic-related noise annoyance in all domains except general health. However, the impact of noise annoyance varied across domains. Table 2 shows the adjusted means of SF-36 scores for the highly exposed subjects, reporting high noise annoyance, and those reporting little noise annoyance.

Table 1 Reported living and housing characteristics of the study sample by gender

\begin{tabular}{|c|c|c|c|c|}
\hline Living and housing characteristics & Total $(n=5,021)$ & Men $(n=2,404)$ & Women $(n=2,617)$ & $P$-value ${ }^{\mathrm{a}}$ \\
\hline Number of persons/household & & & & $<0.001$ \\
\hline Mean (SD) & $2.6(1.4)$ & $2.7(1.4)$ & $2.5(1.39)$ & \\
\hline Neighborhood & & & & 0.03 \\
\hline City/village heavy traffic $(\%)$ & 12 & 11 & 13 & \\
\hline City/village, little to moderate traffic $(\%)$ & 20 & 20 & 20 & \\
\hline Outskirts, heavy traffic $(\%)$ & 22 & 21 & 22 & \\
\hline Outskirts, little to moderate traffic (\%) & 38 & 40 & 37 & \\
\hline Countryside detached $(\%)$ & 8 & 8 & 8 & \\
\hline Median years of residency & 4 & 4 & 4 & 0.37 \\
\hline No double-glazing windows (\%) & 12 & 10 & 14 & $<0.001$ \\
\hline Car traffic density in front of house & & & & $<0.001$ \\
\hline Heavy $(\%)$ & 13 & 12 & 15 & \\
\hline Moderate $(\%)$ & 30 & 28 & 32 & \\
\hline Light $(\%)$ & 56 & 60 & 53 & \\
\hline Heavy vehicle traffic density in front of house & & & & $<0.001$ \\
\hline Constantly (\%) & 8 & 7 & 8 & \\
\hline Often $(\%)$ & 22 & 19 & 24 & \\
\hline Seldom $(\%)$ & 44 & 45 & 44 & \\
\hline Never $(\%)$ & 27 & 29 & 25 & \\
\hline
\end{tabular}

${ }^{a}$ chi-squared test for categorical data, analysis of variance for continuous data $S D$ standard deviation 
Table 2 SF-36-adjusted mean scores and effect estimates in highly and in not noise annoyed participants

\begin{tabular}{|c|c|c|c|c|c|c|}
\hline \multirow[t]{2}{*}{ Mean SF-36 scores } & \multirow{2}{*}{$\begin{array}{l}\text { Highly annoyed }{ }^{\text {a,b }} \\
(n=661)\end{array}$} & \multirow{2}{*}{$\begin{array}{l}\text { Not annoyed }^{\mathrm{a}, \mathrm{c}} \\
(n=2,392)\end{array}$} & \multirow[t]{2}{*}{ RSME } & \multicolumn{3}{|c|}{ Estimated size effects $^{\mathrm{a}, \mathrm{d}}$} \\
\hline & & & & All & Women & Men \\
\hline Physical functioning & 85.8 & 90.7 & 14.3 & -0.34 & -0.22 & -0.59 \\
\hline Role physical & 83.0 & 90.2 & 24.4 & -0.30 & -0.25 & -0.36 \\
\hline Bodily pain & 76.9 & 82.5 & 20.9 & -0.27 & -0.29 & -0.28 \\
\hline General health & 63.6 & 63.5 & 11.7 & 0.01 & 0.01 & 0.01 \\
\hline Vitality & 61.1 & 66.0 & 15.1 & -0.32 & -0.26 & -0.43 \\
\hline Social functioning & 81.3 & 88.76 & 16.7 & -0.44 & -0.51 & -0.55 \\
\hline Role emotional & 77.2 & 90.1 & 24.6 & -0.52 & -0.53 & -0.65 \\
\hline Mental health & 68.5 & 76.6 & 13.8 & -0.58 & -0.53 & -0.65 \\
\hline Mental component summary & 47.1 & 51.3 & 7.6 & -0.54 & -0.55 & -0.54 \\
\hline Physical component summary & 51.4 & 52.3 & 7.1 & -0.13 & -0.07 & -0.26 \\
\hline
\end{tabular}

${ }^{a}$ Multivariate regression adjusted for sex, age, smoking, physical activity, BMI, alcohol consumption, persons in same household, employment status, study center and chronic disease status

${ }^{\mathrm{b}}$ Highly annoyed $=$ reported traffic-related noise annoyance $>8$ on $0-10$ point scale

${ }^{\mathrm{c}}$ Not annoyed $=$ reported traffic-related noise annoyance $=0$ on $0-10$ point scale

e Equals difference between highly and little annoyed divided by RSME of total sample

$R S M E$ root mean square error

Women scored lower in all SF-36 parameters at the lowest level of annoyance and we found different doseresponse curves for men and women, especially for Physical Functioning, Role Physical, Bodily Pain, Mental Health and Social Functioning (Figs. 3a, b, 4a and b and online Fig. 1). The difference lies mainly in the size of reduction in HrQoL at the highest level of annoyance.

There was a significant interaction between sex and noise annoyance in the domains Physical Functioning (lrtest $P=0.013)$, Role Physical $(P=0.008)$ and PCS $(P=0.007)$, and a borderline significant interaction in Mental Health $(P=0.11)$. Also in addition, a significant interaction between chronic disease and noise annoyance in the summary scales, MCS and PCS $(P<0.001)$ was observed. A stratified analysis of the component summary measures in healthy and chronically ill participants showed a reduction of HrQoL scores by noise annoyance in both groups. Irrespective of the level of noise annoyance, scores were lower among the chronically ill subjects, and they declined faster with increasing level of annoyance. Furthermore, the interaction between the years having lived in the same home and traffic-related noise annoyance was investigated. An interaction was found for Physical Functioning (lrtest $P=0.003$ ), Role Physical (lrtest $P=0.022$ ) and Social Functioning domains (lrtest $P=0.061$ ). Stratified analysis by duration, above and equal to or below 6 years, yielded stronger effects estimates in participants who had lived less than 6 years in their homes.

Adjusted effect sizes were calculated by comparing the group of highly annoyed subjects with participants reporting only little annoyance divided by RSME of total sample. The effect sizes varied greatly, ranging from -0.58 to 0.01 (Table 2). Effect sizes were larger in men than in women for Physical Functioning, Role Physical, Role Emotional, Mental Health and PCS.

\section{Discussion}

Our study indicates that traffic-related noise annoyance is significantly associated with lower $\mathrm{HrQoL}$ scores. A reduction of HrQoL scores was present in both genders, although there is evidence for different relationships and thresholds by gender.

Traffic-related noise annoyance is a frequent complaint in the SAPALDIA cohort as well as in the Swiss population. More than half of the study population reported traffic noise annoyance and $13 \%$ a high level of noise annoyance. These results are in accordance with other studies on traffic-related noise annoyance. The Federal Office of the Environment (FOEN) estimates that $64 \%$ of the Swiss population is annoyed by noise and around $14 \%$ of the population is regularly exposed to noise emissions above the Swiss noise emission limits [3]. By comparison, in the European Union $40 \%$ of the inhabitants is exposed to noise levels exceeding $55 \mathrm{dBA}$ in daytime and $30 \%$ at nighttime, associated with considerable noise annoyance [16, 17]. Women, in accordance with their higher percentage of reporting dense traffic at home, reported a significantly higher level of noise annoyance than male participants. Even after adjusting for potential confounders, gender remains an important determinant of traffic-related noise annoyance. Other individual 

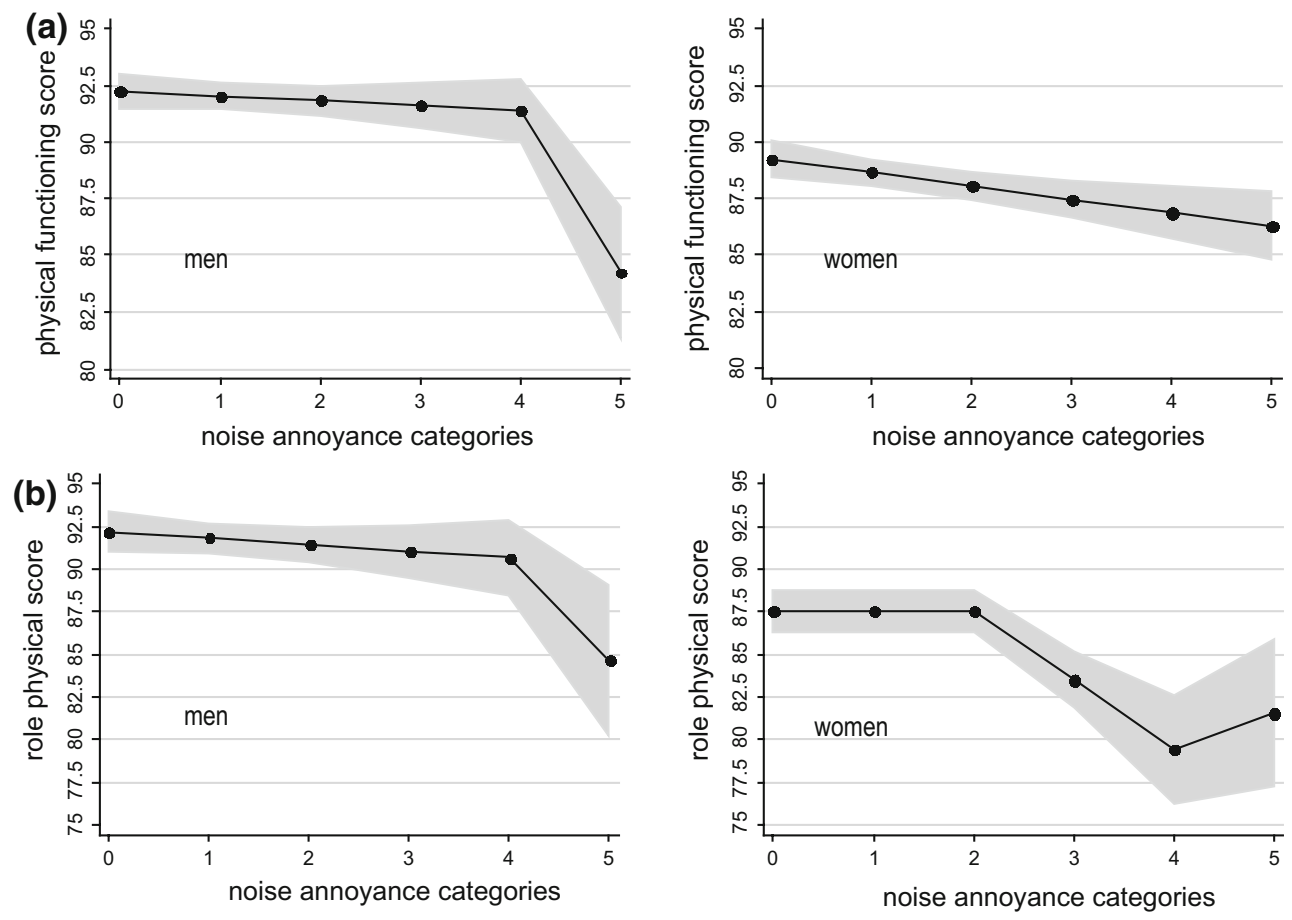

ci95up/ci95lo Linear Prediction

Fig. 3 Linear prediction of noise annoyance impact on a Physical Functioning score and b Role Physical Score, by gender. The linear prediction was adjusted for age, civil status, study area, educational

characteristics, such as age, education, employment status and BMI, were also associated with the highest level of noise annoyance. The significance of these individual factors underlines that noise annoyance cannot be captured by objective measurements of traffic noise alone. Nevertheless, epidemiological studies have shown dose-response relationships between the objective traffic noise emissions and the proportion of people reporting frequent noise annoyance $[17,38]$. Hence, despite the fact that home outdoor noise measurements would have been a gain for the interpretation of the results, noise annoyance is possibly a better marker of the stress-related impact of noise on the well-being of a person, as it combines individual perception, noise sensitivity and disturbance by the exposure [4].

Health-related quality of life and traffic-related noise annoyance

While there is an increasing evidence of the impact of environmental exposures on clinical outcomes, studies on quality of health are scarce. Bridevaux et al. [24] demonstrated that environmental exposure to tobacco smoke was inversely related to $\mathrm{HrQoL}$, with stronger associations in women than that in men. Yen et al. [30] studied the importance of neighborhood problems, including road traffic, and found associations with HrQoL. Studies in status, physical activity, alcohol consumption, BMI, persons in household, neighborhood and chronic disease status

patient populations report a positive relationship between health benefit and higher HrQoL scores. On a population level, even a small improvement in the average $\mathrm{HrQoL}$ score may correspond to a large public health effect. To our knowledge, we are the first to study the association of traffic-related noise annoyance and HrQoL on a national population level. Relying on self-reported data for exposure and outcome can be seen as a limitation to our study. However, HrQoL and annoyance, both highly subjective constructs, can hardly be measured otherwise.

The presented analysis supports our main hypothesis. We found a significant reduction of HrQoL by trafficrelated noise annoyance in both genders in all domains of the SF-36 questionnaire other than the one on general health. Some SF-36 domains showed significant linear relationships with traffic noise annoyance. For others, the relationship was non-linear so that the approximating functions had to be piecewise linear. The respective breakpoints varied by domain and gender. Breakpoints, initiating a stronger decline of the curve, can be interpreted as thresholds for noise tolerance. The cross-sectional character of the data limits the determination of causality. However, the dose-response relationship found in our analyses supports a causal direction of noise annoyance affecting HrQoL. To assess the importance of our findings, we further calculated the effect sizes by comparing the 

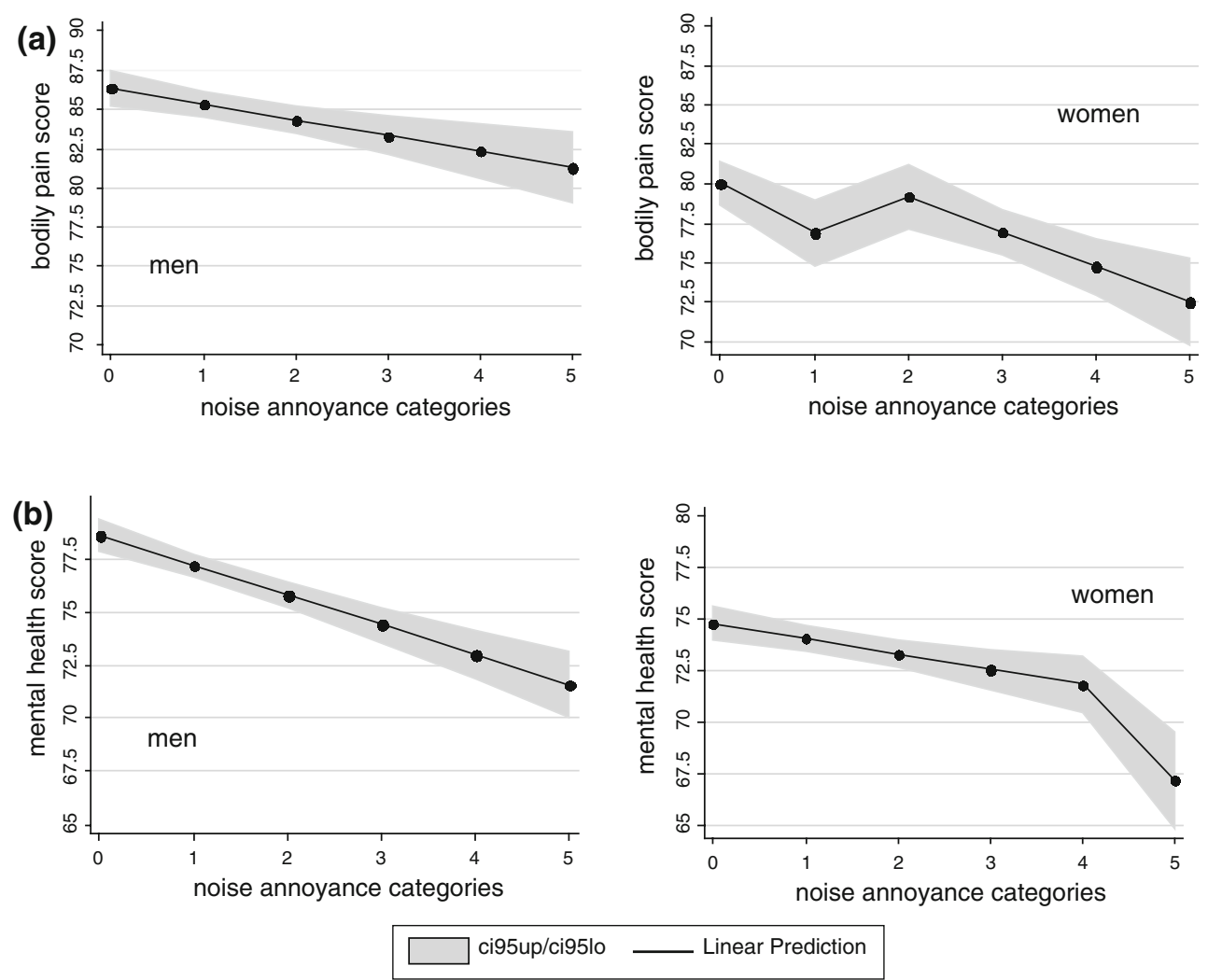

Fig. 4 Linear prediction of noise annoyance impact on a Bodily Pain score and $\mathbf{b}$ Mental Health score, by gender. The linear prediction was adjusted for age, civil status, study area, educational status, physical

activity, alcohol consumption, BMI, persons in household, neighborhood and chronic disease status

adjusted means of HrQoL scores between the highest and the lowest noise annoyance. Several authors recommend to consider an effect size of 0.2 as small, one of 0.5 as medium and one of 0.8 or higher as large, the latter two being thought to represent a meaningful impact [41, 42]. Based on this interpretation, the effect of traffic-related noise annoyance on $\mathrm{HrQoL}$ is meaningful in the domains: Role Emotional, Mental Health and MCS in both men and women. The large database of the SAPALDIA study allowed adjusting for many confounders or effect modifiers. Most important was the thorough adjustment for chronic health conditions. Chronic diseases could confound the association in different ways. A pre-existing disease could be a psychological strain resulting in higher annoyance ratings. Healthy individuals might also cope better with the noise-induced stress and perceive less annoyance and health impact [43]. Further, the duration of exposure corresponding to a higher impact is a biologically plausible hypothesis that could be assessed by including "residential time". We found evidence of interaction between physical functioning, role physical and social functioning and residence time. In contrast to our expectation, the stratified analysis by the time of residency yielded higher effect estimates in those having lived less than 6 years in their

homes. Natural selection of highly sensitive individuals leaving noisy areas or adaption to the noise is potential explanation.

\section{Gender differences}

We hypothesized a gender difference in the association of traffic-related noise annoyance and HrQoL based on current knowledge on gender differences in noise perception, annoyance and HrQoL. Several studies have observed higher noise annoyance scores among women $[15,16]$, and it has been proposed that women have a higher environmental awareness and perception of environmental exposures than men. HrQoL attainment is generally lower in women compared to men $[18,19,21]$. The differences have been explained by a higher consciousness of health complaints or a higher degree of comorbidities in women [18, 23]. While the adverse effect of traffic-related noise annoyance on HrQoL is present in both genders, we see significant effect modification by gender resulting in different thresholds and effect sizes in the domains Physical Functioning, Role Physical, Mental Health and PCS. The average score of Physical Functioning, for example, decreases more strongly in men than in women over the entire range of the noise 
annoyance scale. Moreover, while women report a significant reduction in the Role Physical domain at a moderate noise annoyance level, men perceive a reduction only at the highest levels. Accordingly, the estimated effect sizes in men were higher than that in women. Interaction with gender, only being present in some SF-36 domains, especially in the physical domains, strengthens the results. Major confounding would most probably have affected all domain scores. Although residual confounding can never be excluded, a strength of the SAPALDIA study is detailed information available on chronic diseases and other genderspecific determinants of HrQoL, such as employment status, smoking, BMI and alcohol consumption, allowing for a thorough adjustment of confounding factors.

Women, already experiencing adverse effects of trafficrelated noise annoyance at lower levels and with altogether lower HrQoL scores, are a vulnerable group with regard to noise annoyance and HrQoL. Another vulnerable group to consider is the chronically ill in whom the effects of trafficrelated noise annoyance was also significantly stronger. Chronic diseases were reported more frequently in women. For some SF-36 domains, however, men experienced larger noise-related reductions in $\mathrm{HrQoL}$ and a meaningful effect size in Physical Functioning was found in men only. Although we do see differences by gender in certain domains, a reduction in $\mathrm{HrQoL}$ is present in both men and women, irrespective of their health status.

\section{Conclusion}

This paper presents first evidence of an inverse relationship of traffic-related noise annoyance and $\mathrm{HrQoL}$ in a general population. Women reported high levels of traffic-related noise annoyance more frequently than men, and gender remains a significant determinant of noise annoyance after adjustment for confounders. There is evidence of effect modification by gender for some SF-36 domains, resulting in different effect sizes and suggesting different thresholds of noise tolerance in men and women. Although the estimated reductions are small to moderate, on a population level, considering the predictive value of HrQoL, they may correspond to a meaningful health impact, and noise exposure is likely to increase in our societies. The results underscore the importance of the environment for mental and physical health. Environmental stressors, such as noise pollution, should be considered as covariates when investigating HrQoL. To reduce the adverse health effects by noise pollution, noise abatement strategies should consider noise annoyance as one of the indicators of potentially harmful noise emissions. An objective correlate to the noise annoyance level resulting in a reduction of $\mathrm{HrQoL}$ would facilitate adapting traffic noise emission regulations.
Noise annoyance, however, is not merely explained by noise exposure levels, and addressing the factors influencing the level of noise annoyance may prove to be as important as reducing the actual noise exposure.

Acknowledgments Source of financial support: The study was funded by the Swiss National Science Foundation (grants no 4026-28099, 3347CO-108796, 3247BO-104283, 3247BO-104288, 3247BO-104284, 32-65896.01, 32-59302.99, 32-52720.97, 324253.94); the Federal Office for Forest, Environment and Landscape; the Federal Office of Public Health; the Federal Office of Roads and Transport; the Cantonal Governments of Aargau, Basel-Stadt, BaselLandschaft, Geneva, Lucerne, Ticino, Zurich; the Swiss Lung League; the cantonal Lung Leagues of Basel-Stadt/Basel-Landschaft, Geneva, Ticino and Zurich. Additional contributions: We are indebted to the study participants, the SAPALDIA directorate and scientific team, and the technical and administrative support, medical personal and field workers at the local study sites. This work could not have been done without their commitment.

\section{References}

1. Ouis, D. (2002). Annoyance caused by exposure to road traffic noise: An update. Noise and Health, 4(15), 69-79.

2. Stansfeld, S. A., \& Matheson, M. P. (2003). Noise pollution: Nonauditory effects on health. British Medical Bulletin, 68, 243-257.

3. Bundesamt für Umwelt (BAFU), Bundesamt für Statistik (BFS). Umwelt Report 2007. Neuchatel und Bern; 2007.

4. Babisch, W. (2006). Transportation noise and cardiovascular risk: updated review and synthesis of epidemiological studies indicate that the evidence has increased. Noise and Health, 8(30), 1-29.

5. Bluhm, L. G., Berglind, N., Nordling, E., \& Rosenlund, M. (2007). Road traffic noise and hypertension. Occupational and Environmental Medicine, 64(2), 122-126.

6. Stansfeld, S., Haines, M., \& Brown, B. (2000). Noise and health in the urban environment. Reviews on Environmental Health, 15(1-2), 43-82.

7. de Kluizenaar, Y., Janssen, S. A., van Lenthe, F. J., Miedema, H. M., \& Mackenbach, J. P. (2009). Long-term road traffic noise exposure is associated with an increase in morning tiredness. Journal of the Acoustical Society of America, 126(2), 626-633.

8. Babisch, W. (2005). Environmental Health Perspectives. Noise and Health, 113(1), A14-A15.

9. Ising, H., \& Kruppa, B. (2004). Health effects caused by noise: evidence in the literature from the past 25 years. Noise and Health, 6(22), 5-13.

10. Li, H. J., Yu, W. B., Lu, J. Q., Zeng, L., Li, N., \& Zhao, Y. M. (2008). Investigation of road-traffic noise and annoyance in Beijing: A cross-sectional study of 4th ring road. Archives of Environmental \& Occupational Health, 63(1), 27-33.

11. Guski, R. (1999). Personal and social variables as co-determinants of noise annoyance. Noise and Health, 1(3), 45-56.

12. Kroesen, M., Molin, E. J., \& van Wee, B. (2008). Testing a theory of aircraft noise annoyance: A structural equation analysis. Journal of the Acoustical Society of America, 123(6), 4250-4260.

13. Babisch, W. (2000). Traffic noise and cardiovascular disease: Epidemiological review and synthesis. Noise and Health, 2(8), 9-32.

14. Staples, S. L. (1996). Human response to environmental noise. Psychological research and public policy. American Psychologist, 51(2), 143-150. 
15. Michaud, D. S., Keith, S. E., \& McMurchy, D. (2008). Annoyance and disturbance of daily activities from road traffic noise in Canada. Journal of the Acoustical Society of America, 123(2), 784-792.

16. Passchier-Vermeer, W., \& Passchier, W. F. (2000). Noise exposure and public health. Environmental Health Perspectives, 108(Suppl 1), 123-131.

17. Bluhm, G., Nordling, E., \& Berglind, N. (2004). Road traffic noise and annoyance-an increasing environmental health problem. Noise and Health, 6(24), 43-49.

18. Orfila, F., Ferrer, M., Lamarca, R., Tebe, C., Domingo-Salvany, A., \& Alonso, J. (2006). Gender differences in health-related quality of life among the elderly: The role of objective functional capacity and chronic conditions. Social Science and Medicine, 63(9), 2367-2380.

19. Radoschewski, M., \& Bellach, B. M. (1999). The SF-36 in the Federal Health Survey-possibilities and requirements for application at the population level. Gesundheitswesen, 61, S191S199.

20. Dunn, J. R., Walker, J. D., Graham, J., \& Weiss, C. B. (2004). Gender differences in the relationship between housing, socioeconomic status, and self-reported health status. Reviews on Environmental Health, 19(3-4), 177-195.

21. Gallicchio, L., Hoffman, S., \& Helzlsouer, K. (2007). The relationship between gender, social support, and health-related quality of life in a community-based study in Washington County, Maryland. Quality of Life Research, 16(5), 777-786.

22. Wilson, D. H., Chittleborough, C. R., Kirke, K., Grant, J. F., \& Ruffin, R. E. (2004). The health-related quality of life of male and female heavy smokers. Sozial- und Praventivmedizin, 49(6), 406-412.

23. Banegas, J., López-García, E., Graciani, A., Guallar-Castillón, P., Gutierrez-Fisac, J., Alonso, J., et al. (2007). Relationship between obesity, hypertension and diabetes, and health-related quality of life among the elderly. European Journal of Cardiovascular Prevention and Rehabilitation, 14(3), 456-462.

24. Bridevaux, P. O., Cornuz, J., Gaspoz, J. M., Burnand, B., Ackermann-Liebrich, U., Schindler, C., et al. (2007). Secondhand smoke and health-related quality of life in never smokers: Results from the SAPALDIA cohort study 2. Archives of Internal Medicine, 167(22), 2516-2523.

25. Myint, P. K., Luben, R. N., Surtees, P. G., Wainwright, N. W., Welch, A. A., Bingham, S. A., et al. (2006). Relation between self-reported physical functional health and chronic disease mortality in men and women in the European Prospective Investigation into Cancer (EPIC-Norfolk): A prospective population study. Annals of Epidemiology, 16(6), 492-500.

26. Fan, V., Au, D., Heagerty, P., Deyo, R., McDonell, M., \& Fihn, S. (2002). Validation of case-mix measures derived from self-reports of diagnoses and health. Journal of Clinical Epidemiology, 55(4), 371-380.

27. Rumsfeld, J. S., MaWhinney, S., McCarthy, M., Jr., Shroyer, A. L. W., VillaNueva, C. B., O'Brien, M., et al. (1999). Healthrelated quality of life as a predictor of mortality following coronary artery bypass graft surgery. JAMA, 281(14), 1298-1303.

28. Hofhuis, J. G., Spronk, P. E., van Stel, H. F., Schrijvers, A. J., \& Bakker, J. (2007). Quality of life before intensive care unit admission is a predictor of survival. Crit Care, 11(4), R78.
29. Alonso, J., Ferrer, M., Gandek, B., Ware, J. E., Jr., Aaronson, N. K., Mosconi, P., et al. (2004). Health-related quality of life associated with chronic conditions in eight countries: results from the international quality of life assessment (IQOLA) project. Quality of Life Research, 13(2), 283-298.

30. Yen, I. H., Yelin, E. H., Katz, P., Eisner, M. D., \& Blanc, P. D. (2006). Perceived neighborhood problems and quality of life, physical functioning, and depressive symptoms among adults with asthma. American Journal of Public Health, 96(5), 873-879.

31. Ackermann-Liebrich, U., Kuna-Dibbert, B., Probst-Hensch, N. M., Schindler, C., Felber Dietrich, D., Stutz, E. Z., et al. (2005). Follow-up of the Swiss Cohort Study on Air Pollution and Lung Diseases in Adults (SAPALDIA 2) 1991-2003: Methods and characterization of participants. Sozial- und Praventivmedizin, 50(4), 245-263.

32. Martin, B. W., Ackermann-Liebrich, U., Leuenberger, P., Kunzli, N., Stutz, E. Z., Keller, R., et al. (1997). SAPALDIA: Methods and participation in the cross-sectional part of the Swiss study on air pollution and lung diseases in adults. Sozial- und Praventivmedizin, 42(2), 67-84.

33. Apolone, G., \& Mosconi, P. (1998). The Italian SF-36 health survey: Translation, validation and norming. Journal of Clinical Epidemiology, 51(11), 1025-1036.

34. Bullinger, M. (1995). German translation and psychometric testing of the SF-36 health survey: Preliminary results from the IQOLA project. Social Science and Medicine, 41(10), 13591366.

35. Leplège, A., Ecosse, E., Verdier, A., \& Perneger, T. V. (1998). The French SF-36 health survey: Translation, cultural adaptation and preliminary psychometric evaluation. Journal of Clinical Epidemiology, 51(11), 1013-1023.

36. Ware, J. E. (1994). The SF-36® physical and mental health summary scales: A manual for user's of version 1 (2nd ed.). Lincoln: Quality Metric Inc.

37. Conzelmann-Auer, C., Braun-Fahrlander, C., AckermannLiebrich, U., \& Wanner, H. U. (1993). Perception of traffic noise emission in Basel city canton in comparison to actually measured noise levels. Sozial- und Praventivmedizin, 38(4), 231-238.

38. Hoeger, R., Schreckenberg, D., Felscher-Suhr, U., \& Griefahn, B. (2002). Night-time noise annoyance: State of the art. Noise and Health, 4(15), 19-25.

39. Belojevic, G. A., Jakovljevic, B. D., Stojanov, V. J., Slepcevic, V. Z., \& Paunovic, K. Z. (2008). Nighttime road-traffic noise and arterial hypertension in an urban population. Hypertension Research, 31(4), 775-781.

40. Hosmer, D., \& Lemeshow, S. (1989). Applied logistic regression (1st ed.). New York: Wiley.

41. Cohen, J. (1988). Statistical power analysis for the behavioral sciences. Hillsdale, NJ: Lawrence Erlbaum Associates Publishers.

42. Yost, K. J., Haan, M. N., Levine, R. A., \& Gold, E. B. (2005). Comparing SF-36 scores across three groups of women with different health profiles. Quality of Life Research, 14(5), 12511261.

43. Babisch, W., Ising, H., \& Gallacher, J. E. (2003). Health status as a potential effect modifier of the relation between noise annoyance and incidence of ischaemic heart disease. Occupational and Environmental Medicine, 60(10), 739-745. 